\title{
Influence of androgens on inositol secretion and sperm transport in the epididymis of rats
}

\author{
C. Pholpramool*, R. W. White and B. P. Setchell \\ Department of Physiology, A.R.C. Institute of Animal Physiology, Babraham, \\ Cambridge, CB2 4AT, U.K.
}

\begin{abstract}
Summary. The effects of unilateral efferent duct ligation, bilateral castration or testosterone replacement on the spermatocrit and inositol concentrations in luminal fluid removed by micropuncture from the rat epididymis were investigated. By 5 days after efferent duct ligation, there were substantial falls in the spermatocrit in the caput and corpus, but no change in the cauda. After 7 days there was an increase in the spermatocrit in the cauda. After castration there were more marked reductions in the spermatocrit in the caput and corpus but there was no change in the cauda. The spermatocrit in the corpus, but not in the caput, remained normal when castrated animals were treated with testosterone. The inositol concentrations in luminal fluid from all three sites were not changed after ligation of the efferent ducts but were greatly reduced after castration; this fall was prevented by testosterone treatment. The results support the suggestion that inositol is secrected in the rat epididymis and also indicate that the secretory process is controlled by androgens.
\end{abstract}

\section{Introduction}

It has been known for many years that the secretions of the male reproductive tract of different species contain myo-inositol (Mann, 1951; Hartree, 1957; Setchell, Dawson \& White, 1968). The precise distribution of free myo-inositol in the luminal fluid removed by micropuncture from the testis and epididymis of different mammals has been reported (Hinton, White \& Setchell, 1980). Appreciable concentrations of inositol were found in the seminiferous tubules and rete testis fluid, but the concentration in the testis is trivial compared with the high concentration found in the luminal fluid from the epididymis.

There is little doubt that the inositol present in the testis is synthesized from blood glucose since all the necessary synthetic enzymes are found in the rat testis (Eisenberg, 1967; Robinson \& Fritz, 1979) and there is little uptake of blood inositol into the testis of rams (Middleton \& Setchell, 1972) and rats (Lewin, Yannai, Sulimovici \& Kraicer, 1976). By contrast, it is less certain whether the high concentration of inositol in the epididymis is derived exclusively from the testis or is partly secreted by the epididymal epithelium, although the indirect evidence presently available suggests that inositol may be secreted in the rat epididymis (Lewin et al., 1976; Robinson \& Fritz, 1979; Hinton et al., 1980).

In this study an attempt was made to determine whether myo-inositol is secreted in the rat epididymis and whether the secretion of inositol, if any, is under the influence of androgens.

* Present address: Department of Physiology, Faculty of Science, Mahidol University, Rama VI Rd., Bangkok 4, Thailand. 


\section{Materials and Methods}

Animals. Adult male, Porton-Wistar rats weighing 400-600 g were obtained from the Institute colony and were housed under $14 \mathrm{~h}$ light with free access to food (Oxoid Breeding Diet) and water. They were randomly allocated to 3 groups. Anaesthesia was induced by i.p. injection of pentobarbitone sodium ( $50 \mathrm{mg} / \mathrm{kg}$ body wt: Sagatal, May \& Baker, Dagenham, U.K.). In 18 rats (Group EDL), the efferent ducts on one side were ligated through an abdominal incision leaving the other side and both testes intact. The 27 rats in Group BC were bilaterally castrated, leaving the epididymides intact. The efferent ducts and the testicular artery and veins were ligated on both sides through an abdominal incision and both testes were then removed. In the 25 control rats (Group C) a ligature was placed loosely around the efferent ducts on both sides and then removed, and the abdomen was sutured. All animals were allowed to recover and maintained for 3-21 days. Four rats in Group C and 6 in Group BC received a daily intramuscular injection of sesame oil or testosterone propionate in sesame oil $(5 \mathrm{mg} / \mathrm{kg})$, respectively, for 7 days.

Micropuncture. At 3, 5, 7 and 21 days after the operation, the rats were anaesthetized with an intraperitoneal injection of urethane $(1.2 \mathrm{~g} / \mathrm{kg})$ and prepared for micropuncture of the epididymis as previously described (Hinton, Dott \& Setchell, 1979). Luminal fluid samples were collected from the proximal caput (Site 2), the mid corpus (Site 4) and the proximal cauda (Site 6) and centrifuged at $12000 \mathrm{~g}$ for $30 \mathrm{~min}$ to separate the spermatozoa. Spermatocrit was measured by a micrometer scale in a stereomicroscope and the supernatants were stored at $-20^{\circ} \mathrm{C}$.

Accessory organ weights. At the end of the experiment the epididymis, from which fluid samples had been removed, ventral and dorsolateral prostate glands and seminal vesicles were dissected free of fat and then weighed. The prostate and seminal vesicle glands were emptied of fluid before being weighed.

Inositol assay. Free myo-inositol in the luminal fluid samples was determined by the modified yeast bioassay of White \& Black (1975) as described by Hinton, Setchell \& White (1976) and Hinton et al. (1980) with some additional modifications.

Briefly, duplicate samples $(10-20 \mathrm{nl})$ were transferred into a droplet $(50 \mu \mathrm{l})$ of glass-distilled water positioned at the bottom of a glass test-tube $(6.5 \mathrm{~mm}$ diam., $50 \mathrm{~mm}$ long: G.W.S., London,

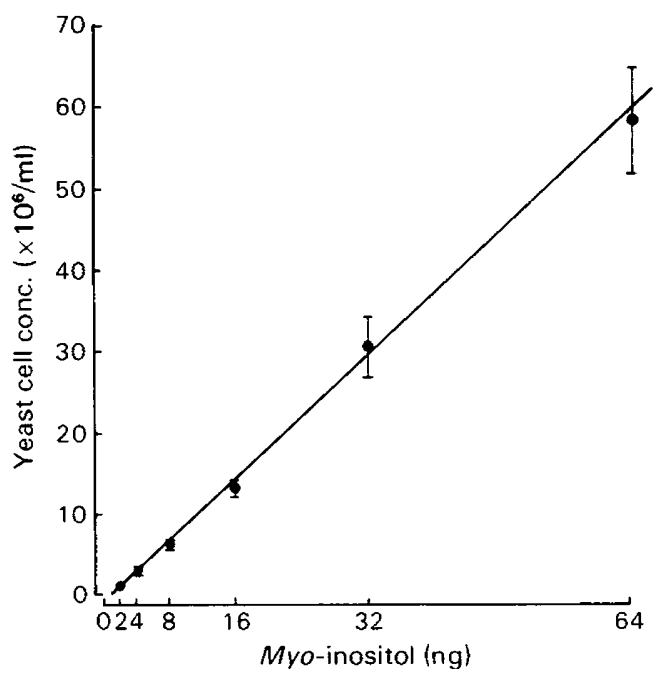

Text-fig. 1. The standard curve for the myo-inositol assay using $K$. brevis. Each value represents mean \pm s.d. from 11 assays. 
U.K.). The tubes were placed in an oven at $80^{\circ} \mathrm{C}$ for $20 \mathrm{~min}$ to dry the sample, and then capped and placed in another oven at $120^{\circ} \mathrm{C}$ for $2-3 \mathrm{~h}$ to be sterilized. Sterile assay medium was prepared by the method of White \& Black (1975), and the inoculum was made by the method of Hinton et al. (1976, 1980) with the exception that the concentration of yeast in the final suspension was adjusted to approximately 4-7 $\times 10^{5}$ cells $/ \mathrm{ml}$. In addition, we found that it was sufficient to seal the glass tubes containing the dried samples and sterile yeast suspension with small pieces of parafilm. This method is much easier and gives more reproducible results than sealing by heat as described by Hinton et al. $(1976,1980)$. The sample tubes were incubated at $25^{\circ} \mathrm{C}$ for 3 days and thoroughly mixed twice a day. A set of standard samples containing myo-inositol (2-64 ng) was similarly prepared in duplicate. The numbers of yeast cells in the samples and standards were counted at the end of the incubation period as described by Hinton et al. (1980). The standard curve obtained from 11 assays is shown in Text-fig. 1 . In one assay, the standard deviation of 10 replicate determinations of $15-25 \mathrm{ng}$ inositol was 2.96 .

Testosterone assay. Blood samples were removed from the jugular vein or by cardiac puncture of some of the rats in Group $\mathrm{C}$ and EDL at the end of experiments and kept overnight in a cold room $\left(4^{\circ} \mathrm{C}\right)$. Serum samples were separated by centrifugation and assayed for testosterone as previously described by Main, Davies \& Setchell (1978).

Statistical analyses. Differences between groups were compared by using Student's $t$ test and analysis of variance. Unless otherwise indicated the level of significant difference is at $P<0.05$ throughout. All data are presented as mean \pm s.e.m.

\section{Results}

\section{Effect of unilateral efferent duct ligation}

When the flow of fluid from the testis into the epididymis was prevented by ligation of the efferent ducts, a marked decrease in spermatocrit occurred in the proximal caput and mid corpus, but not in the proximal cauda (Group EDL, Table 1). Decreases were apparent by 5 days after efferent duct ligation in the fluids removed from the proximal caput and mid corpus, and further

Table 1. Changes in the spermatocrit of luminal fuid removed from various segments of the rat epididymis after efferent duct ligation, castration and castration + testosterone (see Hinton, et al., 1979, for the sites of puncture)

\begin{tabular}{|c|c|c|c|c|}
\hline \multirow[b]{2}{*}{ Treatment } & \multirow[b]{2}{*}{ Days after } & \multicolumn{3}{|c|}{ Spermatocrit (\%) } \\
\hline & & $\begin{array}{l}\text { Proximal caput } \\
\quad \text { (Site 2) }\end{array}$ & $\begin{array}{l}\text { Mid corpus } \\
\quad(\text { Site 4) }\end{array}$ & $\begin{array}{l}\text { Proximal cauda } \\
\quad \text { (Site 6) }\end{array}$ \\
\hline \multirow{3}{*}{ Sham (control) } & 3 & $24 \cdot 0 \pm 3 \cdot 2(4)$ & $31.6 \pm 2.4(4)$ & $39.8 \pm 3.0(4)$ \\
\hline & 5 & $22.3 \pm 1.7(8)$ & $31.9 \pm 1.3(8)$ & $42.5 \pm 1.8(8)$ \\
\hline & 7 & $23.1 \pm 1.6(7)$ & $29.8 \pm 0.7(8)$ & $38.7 \pm 1.7(8)$ \\
\hline \multirow[t]{3}{*}{ Efferent duct ligation } & 5 & ${ }^{* 9.2} \pm 2.8(7)$ & ${ }^{*} 23.5 \pm 1.4(7)$ & $41 \cdot 7 \pm 1 \cdot 3(7)$ \\
\hline & 7 & ${ }^{*} 1.7 \pm 0.3(6)$ & $* 20.4 \pm 1.1(7)$ & $* 45.7 \pm 1.8(7)$ \\
\hline & 21 & ${ }^{*} 1.8 \pm 0.1(4)$ & $* 5.7 \pm 0.8(4)$ & $* 47.4 \pm 2.9(4)$ \\
\hline \multirow[t]{3}{*}{ Castration } & 3 & $* 9.8 \pm 2.4(3)$ & $27 \cdot 7 \pm 4 \cdot 0$ & $37.6 \pm 1.4(4)$ \\
\hline & 5 & $* 4 \cdot 1 \pm 2 \cdot 2(7)$ & $\dagger * 7.8 \pm 3.5(4)$ & $42 \cdot 6 \pm 4 \cdot 5(7)$ \\
\hline & 7 & $* 5.9 \pm 5.9(2)$ & $+* 4 \cdot 2 \pm 2 \cdot 3$ & $\dagger 31.9 \pm 5.3(8)$ \\
\hline Sham + oil & 7 & $22.4 \pm 1.9(4)$ & $32 \cdot 8 \pm 2 \cdot 3(4)$ & $44.5 \pm 4.0(4)$ \\
\hline Castration + testosterone in oil & 7 & $* 6.8 \pm 2.2(6)$ & $22.5 \pm 5.4(6)$ & $\ddagger 48.7 \pm 4.5(6)$ \\
\hline
\end{tabular}

Values are mean \pm s.e.m. for the no. of observations in parentheses.

* Significantly different from corresponding control value, $P<0.05$.

+ Significantly different from corresponding values in Group EDL, $P<0.05$.

$\ddagger$ Significantly different from corresponding value in the castration group, $P<0.05$. 
reductions in the spermatocrit were noted by 7 and 21 days respectively after ligation of the efferent ducts. In contrast, spermatocrit in the proximal cauda was increased slightly by 7 days after ligation of the efferent ducts and this elevation was maintained even after 3 weeks.

There were no changes in the concentrations of inositol in the fluids removed from any of the three sites at 5 or 7 days after efferent duct ligation (Table 2). However, by 21 days inositol concentrations in the proximal caput and proximal cauda were significantly increased (Table 2).

Table 2. Mean \pm s.e.m. (no. of observations) concentrations of free myo-inositol in the luminal fluid removed from various segments of the rat epididymis after efferent duct ligation, castration and castration + testosterone (see Hinton et al., 1979, for the sites of puncture)

\begin{tabular}{|c|c|c|c|c|}
\hline \multirow[b]{2}{*}{ Treatment } & \multirow[b]{2}{*}{ Days after } & \multicolumn{3}{|c|}{ Inositol concentration (mM) } \\
\hline & & $\begin{array}{l}\text { Proximal caput } \\
\quad \text { (Site 2) }\end{array}$ & $\begin{array}{l}\text { Mid corpus } \\
\quad \text { (Site 4) }\end{array}$ & $\begin{array}{l}\text { Proximal cauda } \\
\quad \text { (Site 6) }\end{array}$ \\
\hline Sham (control) & $\begin{array}{l}3 \\
5 \\
7\end{array}$ & $\begin{array}{l}12.5 \pm 1.3(4) \\
11.8 \pm 1.4(9) \\
13.2 \pm 1.2(8)\end{array}$ & $\begin{array}{r}10.1 \pm 0.7(4) \\
9.2 \pm 0.5(7) \\
10.1 \pm 0.7(7)\end{array}$ & $\begin{array}{l}28.4 \pm 2.3(4) \\
26.3 \pm 2 \cdot 1(7) \\
22.8 \pm 2.1(8)\end{array}$ \\
\hline Efferent duct ligation & $\begin{array}{r}5 \\
7 \\
21\end{array}$ & $\begin{array}{r}13.6 \pm 0.8(7) \\
11.6 \pm 1.6(7) \\
* 19.6 \pm 2.5(3)\end{array}$ & $\begin{array}{r}10.4 \pm 0.5(7) \\
8.1 \pm 0.9(7) \\
9.2 \pm 0.2(4)\end{array}$ & $\begin{array}{r}23.9 \pm 2.4(7) \\
24.2 \pm 1.7(7) \\
* 39.0 \pm 2.5(4)\end{array}$ \\
\hline Castration & $\begin{array}{l}3 \\
5 \\
7\end{array}$ & $\begin{array}{r}14.9 \pm 1.0(4) \\
\dagger^{*} 3.7 \pm 1.1(7) \\
\dagger^{*} 1.6 \pm 0.8(3)\end{array}$ & $\begin{array}{r}13.0 \pm 0.9(3) \\
\dagger^{*} 4.0 \pm 2.6(4) \\
\dagger^{*} 2.3 \pm 1.1(6)\end{array}$ & $\begin{array}{r}{ }^{*} 20.6 \pm 1.8(4) \\
\dagger^{*} 15.3 \pm 1.4(7) \\
\dagger^{*} 15.8 \pm 1.8(9)\end{array}$ \\
\hline $\begin{array}{l}\text { Sham }+ \text { oil } \\
\text { Castration }+ \text { testosterone in oil }\end{array}$ & $\begin{array}{l}7 \\
7\end{array}$ & $\begin{array}{r}12.2 \pm 0.7(4) \\
\ddagger 14.7 \pm 1.6(6)\end{array}$ & $\begin{array}{r}11.5 \pm 0.5(4) \\
\ddagger 11.7 \pm 1.3(6)\end{array}$ & $\begin{array}{r}26.2 \pm 1.9(4) \\
\ddagger 22.7 \pm 2.0(6)\end{array}$ \\
\hline
\end{tabular}

* Significantly different from corresponding control value, $P<0.05$.

$\dagger$ Significantly different from corresponding value in Group EDL, $P<0.05$.

$\ddagger$ Significantly different from corresponding value in the castration group, $P<0.05$.

Although the epididymis decreased in size and weight $(\mathrm{g})$ by 21 days after ligation of the efferent ducts (Group C: 3 days, $0.52 \pm 0.013(\mathrm{~N}=4) ; 5$ days, $0.54 \pm 0.011(\mathrm{~N}=9) ; 7$ days, $0.54 \pm 0.023$ $(\mathrm{N}=8)$; Group EDL: 5 days, $0.52 \pm 0.018(\mathrm{~N}=7) ; 7$ days, $0.48 \pm 0.019(\mathrm{~N}=7) ; 21$ days, $0.38 \pm$ $0.014(\mathrm{~N}=4))$, the tubular lumen was still patent and serum testosterone $(\mathrm{ng} / \mathrm{ml})$ was in the normal range (Group C: 7 days, $2 \cdot 6 \pm 0 \cdot 1(\mathrm{~N}=2)$; Group EDL: 5 days, $3 \cdot 6 \pm 0 \cdot 2(\mathrm{~N}=6) ; 7$ days, $3.5 \pm$ $0 \cdot 2(\mathrm{~N}=6) ; 21$ days, $3 \cdot 4 \pm 0 \cdot 4(\mathrm{~N}=4))$.

\section{Effect of bilateral castration}

The complete removal of testicular androgens in addition to a blockage of the flow of testicular fluid into the epididymis caused an additional fall in spermatocrit in the mid corpus by 5 and 7 days after castration (Group BC, Table 1). There were no differences between Groups EDL and BC in the changes in spermatocrit seen in the proximal caput 5 and 7 days after operation. However, a fall in the spermatocrit in this area could be found as early as 3 days after castration. On the other hand, the spermatocrit in the proximal cauda was not changed after castration, at least during the period studied.

By 3 days after castration the concentrations of inositol in the proximal caput and mid corpus were not reduced but that in the proximal cauda showed a small decrease (Table 2). However, removal of blood-borne androgens as well as blocking the flow of testicular fluid caused a marked decrease in the inositol concentration in the caput and corpus by 5 days after operation, and these changes became more marked by 7 days. The fall in inositol in the caput and corpus was greater than that in the proximal cauda. By Day 7 the inositol concentrations in the caput, corpus and 
cauda in the castrated rats were $12 \cdot 1,22 \cdot 8$ and $69 \cdot 3 \%$ of those in Group C and $13 \cdot 8,28 \cdot 4$ and $65 \cdot 3 \%$ of those in Group EDL respectively.

The weight of the epididymis $(\mathrm{g})$ was decreased by 5 days after castration ( 3 days, $0.52 \pm 0.035$ $(\mathrm{N}=4) ; 5$ days, $0.36 \pm 0.027(\mathrm{~N}=8), P<0.001 ; 7$ days, $0.27 \pm 0.011(\mathrm{~N}=9), P<0.001$; see above for control values). The tubular lumen appeared normal in size 5 days after castration but was appreciably smaller by 7 days and samples were more difficult to obtain, especially from the caput and corpus.

\section{Effect of testosterone replacement}

Treatment with testosterone did not prevent the fall in spermatocrit in the proximal caput but it was effective in the mid corpus (Table 1). The spermatocrit value in the proximal cauda was not different from that in Group C (sham + oil) or Group EDL.

However, this dose of testosterone $(5 \mathrm{mg} / \mathrm{kg}$ ) effectively raised the inositol concentrations in all three sites to the control values (Table 2). The post-castration reduction in the weights of the epididymis and ventral prostate gland was completely prevented by testosterone, and the dorsolateral prostate gland and seminal vesicle glands were significantly enlarged (Table 3 ). The testosterone concentrations achieved in the peripheral blood $(24 \cdot 7 \pm 5.0 \mathrm{ng} / \mathrm{ml}, n=6)$ were considerably higher than normal.

Table 3. Effects of castration and testosterone replacement on the accessory organ weight

\begin{tabular}{|c|c|c|c|c|c|}
\hline \multirow[b]{2}{*}{ Treatment } & \multirow[b]{2}{*}{$\begin{array}{l}\text { Days } \\
\text { after }\end{array}$} & \multicolumn{4}{|c|}{ Accessory organ weights $(\mathrm{g})$} \\
\hline & & Epididymis & $\begin{array}{l}\text { Ventral } \\
\text { prostate }\end{array}$ & $\begin{array}{l}\text { Dorsolateral } \\
\text { prostate }\end{array}$ & Seminal vesicle \\
\hline Sham + oil & 7 & $0.59 \underset{(4)}{ \pm} 0.01$ & $0.51 \underset{(4)}{ \pm} 0.06$ & $0 \cdot 16 \underset{(4)}{ \pm} 0 \cdot 01$ & $0.71 \underset{(4)}{ \pm} 0.09$ \\
\hline Castration & 3 & $0.52 \underset{(4)}{ \pm 0.04}$ & $0.29 \pm 0.02$ & $0.20 \underset{(2)}{ \pm} 0.05$ & $0.49 \underset{(2)}{ \pm} 0.02$ \\
\hline $\begin{array}{l}\text { Castration }+ \\
\text { testosterone } \\
\text { in oil }\end{array}$ & 7 & $0.56 \underset{(6)}{ \pm} 0.01$ & $0.65 \underset{(6)}{ \pm} 0.07$ & ${ }^{*} 0.29 \underset{(6)}{ \pm} 0.03$ & ${ }^{*} 1.13 \underset{(6)}{ \pm} 0.04$ \\
\hline
\end{tabular}

Values are mean \pm s.e.m. for the no. of observations in parentheses.

* Significantly different from sham \pm oil value, $P<0.05$.

\section{Discussion}

The results demonstrate that blockage of the flow of testicular fluid by ligation of the efferent ducts did not alter inositol concentration in the epididymis despite the fact that the spermatocrit was markedly reduced. This indicates that inositol is secreted in all regions of the epididymal duct. It is not known, however, whether inositol present in the luminal fluid is derived from blood glucose as in the testis or from blood inositol. There is evidence that the rat epididymis contains all the enzymes necessary for the biosynthesis of inositol from glucose (Robinson \& Fritz, 1979), although a 12-fold accumulation of blood inositol in the rat epididymis has also been reported (Lewin et al., 1976). Rat epididymal spermatozoa have no ability to synthesize inositol (Eisenberg \& Bolden, 1964).

The secretion of inositol in the epididymis is androgen dependent since the inositol concentration is substantially decreased after castration compared with the values after efferent duct ligation when serum testosterone is normal. The inositol levels are also restored by exogenous testosterone, 
suggesting that the level of testosterone in the peripheral circulation is more important than that in the luminal fluid in maintaining inositol secretion. In addition, there appears to be a regional difference in the androgen-dependent inositol secretion in the rat epididymis; after castration inositol secretion in the caput and corpus is almost completely abolished, whereas an appreciable amount of inositol is still secreted in the proximal cauda, suggesting that, at that site, it is only partly androgen-dependent. However, it is also possible that the inositol secretion in the proximal cauda may have stopped after castration but there could be considerable residual inositol still present, possibly due to a lower rate of fluid flow down the lumen through this segment compared with the proximal regions. Indeed, the spermatocrit data support this view because after castration a substantial reduction in spermatocrit is evident in both the caput and the corpus but not in the cauda.

Changes in spermatocrit values in any segment of the epididymis are due to changes in sperm transport into and/or out of that region or to changes in water transport across the epididymal duct since it has been shown that resorption of spermatozoa does not occur in the epididymis (Bedford, 1975; Moore \& Bedford, 1978; Temple-Smith \& Bedford, 1978). After ligation of the efferent ducts for 14-21 days water reabsorption in the perfused rat epididymis is unchanged (Wong, Au \& Ngai, 1978). Therefore, the reductions in spermatocrit in the proximal caput and mid corpus after efferent duct ligation for 5-21 days are primarily accounted for by a blockage of sperm transport from the testis. However, it is difficult to explain an elevation of spermatocrit in the proximal cauda unless it is proposed that transfer of spermatozoa out of the cauda is depressed or movement of spermatozoa from the proximal regions is enhanced. In view of the previous findings that ligation of the efferent ducts did not alter the spontaneous contractility of the distal cauda epididymidis in the rat (Hib \& Ponzio, 1977) the latter possibility is more likely. After castration, however, water reabsorption in the epididymis is inhibited (Wong \& Yeung, 1978; Wong et al., 1978) and this could explain the lower spermatocrit values in the corpus and cauda after castration compared with those after efferent duct ligation, and the restoration of normal values for spermatocrit in the corpus and cauda by administration of testosterone. It is not surprising that the spermatocrit in the proximal caput was still decreased after testosterone replacement since entry of spermatozoa into that region would be abolished by removal of the testis. The changes in fluid resorption may not be the whole explanation, as changes in duct motility could also affect the spermatocrit, but the effects so far reported of castration on epididymal duct motility (Hib \& Ponzio, 1977) in fact are in the opposite direction.

In conclusion, we have shown by micropuncture study that free myo-inositol is secreted in all regions of the rat epididymis. The secretion of inositol is regulated by circulating androgens from the testis. It remains to be answered, however, whether inositol in the luminal fluid is derived from blood glucose or blood inositol.

We thank Mr K. A. A. Galil for help with the testosterone assay and Mrs Kosoom Vongthai for typing this manuscript. This work was supported by the World Health Organization. C.P. is the recipient of a Research Training Grant from W.H.O.

\section{References}

Bedford, J.M. (1975) Maturation, transport, and fate of spermatozoa in the epididymis. In Handbook of Physiology, Section 7: Endocrinology, Vol. 5: Male Reproductive System, pp. 303-318. Eds D. W. Hamilton \& R. O. Greep. American Physiological Soc., Washington, D.C.

Eisenberg, F., Jr (1967) D-myo-inositol-1-phosphate as product of cyclization of glucose-6-phosphate and substrate for a specific phosphatase in rat testis. $J$. biol. Chem. 242, 1375-1382.
Eisenberg, F., Jr \& Bolden, A.H. (1964) Reproductive tract as site of synthesis and secretion of inositol in the male rat. Nature, Lond. 202, 599-600.

Hartree, E.F. (1957) Inositol in seminal plasma. Biochem. J. 66, 131-137.

Hib, J. \& Ponzio, R.O. (1977) Effect of efferent duct ligation, gonadectomy and testosterone replacement on epididymal contractility in the rat. J. Reprod. Fert. 50, 327-329. 
Hinton, B.T., Setchell, B.P. \& White, R.W. (1976) The determination of myo-inositol in micropuncture samples from the testis and epididymis of the rat. J. Physiol., Lond. 265, 14-15P.

Hinton, B.T., Dott, H.M. \& Setchell, B.P. (1979) Measurement of the motility of rat spermatozoa collected by micropuncture from the testis and from different regions along the epididymis. $J$. Reprod. Fert. 55, 167-172.

Hinton, B.T., White, R.W. \& Setchell, B.P. (1980) Concentrations of myo-inositol in the luminal fluid of the mammalian testis and epididymis. J. Reprod. Fert. 58, 385-399.

Lewin, L.M., Yannai, Y., Sulimovici, S. \& Kraicer, P.F. (1976) Studies on the metabolic role of myo-inositol. Distribution of radioactive myo-inositol in the male rat. Biochem. J. 156, 375-380.

Main, S.J., Davies, R.V. \& Setchell, B.P. (1978) Feedback control by the testis of gonadotrophin secretion: an examination of the inhibin hypothesis. $J$. Endocr. 79, 255-270.

Mann, T. (1951) Inositol, a major constituent of the seminal vesicle secretion of the boar. Nature, Lond. 168, 1043-1044.

Middleton, A. \& Setchell, B.P. (1972) The origin of inositol in the rete testis fluid of the ram. J. Reprod. Fert. 30, 473-475.
Moore, H.D.M. \& Bedford, J.M. (1978) Fate of spermatozoa in the male. I. Quantitation of sperm accumulation after vasectomy in the rabbit. Biol. Reprod. 17, 784-790.

Robinson, R. \& Fritz, I.B. (1979) Myoinositel biosynthesis by Sertoli cells, and levels of myoinositol biosynthetic enzymes in testis and epididymis. Can. $J$. Biochem. 57, 962-967.

Setchell, B.P., Dawson, R.M.C. \& White, R.W. (1968) The high concentrations of free myo-inositol in rete testis fluid from rams. J. Reprod. Fert. 17, 219-220.

Temple-Smith, P.D. \& Bedford, J.M. (1978) Fate of spermatozoa in the male: II. Absence of a specific sperm disposal mechanism in the androgen-deficient hamster and rabbit. Biol. Reprod. 17, 791-798.

White, R.W. \& Błack, M.E. (1975) Assay of myo-inositol using the yeast Kloeckera apiculata (K. Brevis). In Some Methods for Micro-biological Assay, pp. 129136. Eds R. G. Board \& D. W. Lovelock. Academic Press, London.

Wong, P.Y.D. \& Yeung, C.H. (1978) Absorptive and secretory functions of the perfused rat cauda epididy. midis. J. Physiol., Lond. 275, 13-26.

Wong, P.Y.D., Au, C.L. \& Ngai, H.K. (1978) Electrolyte and water transport in rat epididymis; its possible role in sperm maturation. Int. J. Androl., Suppl. 2, $608-627$. 